\title{
14. General theory for managing contracts in public service delivery: towards collaborative contractual frameworks
}

\author{
Isha Dayal ${ }^{1}$
}

\section{INTRODUCTION: PUBLIC ADMINISTRATION REFORMS}

The study of public administration goes back to the late nineteenth century with a focus on efficiency through a rule-based 'hierarchical' bureaucratic structure (Wilson 1887; Weber 1922). The period of the 1970s to 1980s saw a change from traditional public administration towards more business-like competitive provision of public goods and services (Osborne 2006). While efficiency and economy has always been the core objective of public administration, the methods towards achieving the same have widely differed between the former traditional mode of public administration and the recent New Public Management (NPM). Efficiency and economy under traditional public administration was associated with public employees' strict organizational rule abidance, conformity with prescribed actions, and a strong sense of discipline, which were promoted to increase reliability in the behaviour of employees (Taylor 1912; Weber 1922). Such behavioural 'control' could be seen as a method to promote alignment between the goals and interests of the bureaucratic principals and agents. However, this very emphasis on stringent bureaucratic structure and resulting 'bureaucratic personalities' led to declining public confidence in the government (Perry and Wise 1990). Delays and inefficiencies in public dealings, providing 'categorical treatment' to all clients, inflexibilities in handling individual instances and difficulties in adapting to new skills and conditions, all had made 'red-tape' a norm at public sector agencies (Merton 1940).

Dire cry from the public towards improving governance coincided with the period of introduction of public choice theory and the study of new institutional economics (Buchanan and Tullock 1962; Widmalm 2016). Public choice is an economic theory widely used in the study of political science. This meant 
applying theories relating to the 'market' to a non-market setting; thereby bringing in greater competition, efficiency, and focus on 'performance' to turn a bureaucratic public sector more 'business' like. A result of this marriage between managerialism and new institutional economics was the introduction of several new features in public administration involving decentralization, privatization, performance measurement, competition and choice (Aoki 2015). This new form of governance, aimed at achieving the very efficiency in public service which traditional public administration failed to reach, came to be known as New Public Management (Hood 1991).

A peculiar feature of NPM lies in its emphasis towards private or decentralized provision of public services (Amagoh 2009; Aoki 2015). The agents of public service delivery, viz. private sector or local government, are considered more competitive and efficient than the centralized public sector in provision of goods and services. The increased competition through competitive contracting is believed to help provide services economically by lowering costs (Milward and Provan 2003: 6), and with greater allocative efficiency by delegating power and autonomy to local governments through decentralization (Oates 1972). At the same time, measuring performance is seen as important not only to improve internal activities, but also to determine if the private or local public agents are performing to the standards expected by the principals (Behn 2003).

As will be discussed in more detail in the forthcoming sections, several authors have questioned the success and spread of NPM or even regarded it as 'dead' (Manning 2001; Dunleavy et al. 2006). NPM has been criticized for being restricted geographically (Pollitt 2001), largely within the developed countries, having made little influence on the public administration in developing countries. There have been inefficiencies and accountability failures recorded in its mode of service provision as well (Romzek and Dubnick 1998; Vigoda 2002; Kelly 2005). Involvement of multiple agents through decentralization and 'outside' agents through privatization are seen to have especially led to agency problems (Ferris 1992; Kane and Patapan 2006). Emerging from the failures of 'managerialism"2 and 'adversarialism' ${ }^{3}$ (Ansell and Gash 2008) in achieving efficiency, and an increased emphasis on making public administration representative and politically accountable to the citizens (Kaufman 1956), collaborative governance brings forth a novel 'hybrid' form of governance which is restricted to not just the public and private sectors, but opens up public provision to the civil society, NGOs and wider public as well (Osborne 2006; Emerson, Nabatchi and Balogh 2012). Regarding the relations shared between the entities involved in provision of public goods under collaborative governance, the structure focuses on cooperation rather than conflict, importance of leadership over hierarchy, on effectiveness by heeding to societal needs, and most importantly on constant feedback learning 
to improve future service delivery (Emerson, Nabatchi and Balogh 2012). The aspect of learning leading to improvement in the 'management', itself makes collaborative governance rather dynamic and adaptive unlike the traditional public administration and NPM (Emerson, Nabatchi and Balogh 2012).

Agency theory segregates contracts as behaviour-based and outcome-based (Eisenhardt 1989). However, there is little clarity in the literature thus far as to which form of contract must be optimal for a given situation or administrative mode in order to raise managerial capacity and achieve maximum efficiency in public service delivery. In addition, there has been very little empirical research regarding principal-agent problems and contracts in the public sector (Eisenhardt 1989). Drawing on the theories of public administration and principal-agent, and the available empirical literature on agency and contracts, the chapter has been written under the epistemological lens of post-modernism by taking a pragmatic approach towards synthesizing the literature, creating new knowledge, and presenting certain propositions for future empirical research (Cunningham and Flitzgerald 1995). The chapter is guided towards theory building, while simultaneously contributing to the fields of public administration, agency and contracts. In doing so, it highlights the need to revisit the application of principal-agent theory, especially in the evolving nature of public administration and changing modes of governance (Osborne 2006). In line with the focus of this volume, the chapter attempts to provide a nuanced distinction between the different modes of governance and collaboration (Kekez, Howlett and Ramesh, Chapter 1 in this volume). It aims to achieve this by focusing on the relations shared between the actors in an administrative arrangement and thus the most optimal contract that can be drawn for increasing their managerial capacities to achieve efficiency in public service delivery.

Put simply, principal-agent problem exists when there is imperfect information between the entities involved in delegating the task, that is, principal(s), and those performing the task, that is, agent(s) (Laffont and Martimort 2009: 12). Contracts are needed to incentivize the agents to perform the task according to the requirements of the principal (Laffont and Martimort 2009: 18). When principals have a greater control over the behaviour of agents, the contracts must tend towards behaviour-based. However, when the behaviour of agents cannot be monitored but the outcome can be measured, the contracts must tend towards being outcome-based. This line of reasoning has previously been explored by linking principal-agent theory to new institutional economics perspectives. It explains how different types of contracts are used by firms under different transactional settings to motivate agents to do what the principal desires - firms using monitoring mechanisms are bureaucratic, those relying on 'high-powered incentives' are risk-taking innovators, and those relying on cooperation are 'team oriented' (Ménard and Shirley 2005: 11). It 
is not difficult to see how the three can intuitively be translated to the stages in public administration, the three modes of governance (hierarchy, market and collaboration), and the respective contractual solutions drawn out to overcome agency problems, raise managerial capacity, and achieve efficiency.

By undertaking a thorough review of the literature, this chapter explores if reforms and different modes of public administration have a determining role on the contractual relations shared between the principal and agent(s). The exercise can be seen as providing a method to identify the actors involved in public service delivery, and the relations shared between them. This translates to a method that can distinguish governance modes, and fulfil efficiency in public service delivery by designing effective contracts.

Under traditional public administration wherein in-house agent behaviour can easily be monitored, contracts are likely to be behaviour-based. While under NPM, especially with its roots in market-based efficiency through involvement of 'outside agents' - that make monitoring agents' behaviour uneconomical but there is a measure of performance - the contractual relations too should see a digression from pure behaviour-based towards outcome-based contracts. Looking forward, a peculiar feature that comes about under collaborative governance is the dispensing of 'managerialism' and 'adversarialism' and a notion of 'shared norms'. This blurs the roles and conflict between 'principal' and 'agent', which would make principal-agent theory and the requirement of contracts for provision of public goods and services, theoretically, rather redundant. However, if contracts continue to be drawn in practice, contract theory must be separated from the theories of principal-agent and agency, to include more collaborative or relational contractual arrangements (Eisenhardt 1989; Osborne 2006). At the same time, there is an increased need to focus on the actors in the collaboration, and the agent taking the lead, to draw implications on the types of collaborative contracts, and how they may differ from outcome- or behaviour-based contracts.

Though there is a wide literature on different stages of public administration, principal-agent theory, agency theory, and contract theory, this study aims to synthesize these to understand if there could be an intricate linkage between them. Along with determining the optimal contract under a specific governance mode, the synthesis could also throw light on whether principal-agent theory, agency theory and traditional contracts would slowly lose their significance with continuous reforms in public administration and the gradual push towards more collaborative and participatory forms of governance, wherein the very absence of a principal-agent problem can help raise the managerial capacity of the actors involved and make public service delivery more effective.

Before one begins to assume traditional public administration and NPM as bygones, this section serves as an important cautionary note in the quest towards building a general theory of contracts in public administration. One 
must acknowledge that despite the literature's presentation of rather sequential $^{4}$ reforms in public administration, and of the mode of administration being in line with the bureaucratic or regime values existing at the time (Rohr 1979; Mosher 1982; Mengistu and Vogel 2006; Osborne 2006) - the distinction between all of these administrative stages is not as clear-cut. Although we have particular features and principles of traditional public administration and NPM laid out by Weber (1922) and Hood (1991) respectively, the scholars have themselves been cognizant of the 'non-universality' and non-applicability of all of the governing principles in a given instance. In more recent times, some other scholars have gone on to argue how the features of each of these governance modes may be present 'simultaneously' (Pollitt 2016). The argument can further be supported by institutional theory wherein existing established institutions ${ }^{5}$ of public administration may either resist change or with time evolve into completely new institutions due to external isomorphic pressures (Dacin, Goodstein and Scott 2002). It can explain why despite international pressures, convergence in public administration institutions has not occurred, and rather we see co-existence of different institutional features, or emergence of new institutions altogether (Pollitt 2001; Painter and Peters 2010). This can explain the rise of collaborative modes of public service delivery and the institutions supporting the same, which as in the introductory chapter to the volume, can even been described as a mix of hierarchy, market and network forms of governance.

Thus, rather than making hierarchies, traditional public administration and therefore behaviour-based contracts a passé, the aforementioned note points at how the theoretical claim can continue to be relevant in contemporary times. This is to say, that the proposed causal linkage between the governance modes and types of contracts must be tested, not over time, but perhaps across different sectors and public goods and services under consideration.

Future research can be directed towards testing the derived propositions in different sectors of public service delivery to provide an empirical backing to the general theory of contracts in public administration.

The next section examines the empirical literature which links different features of tasks performed by the agents with the optimal contract decided by the principals. The section goes on to explore the role of incentives and ownership to see how they can have an important bearing on the design of contracts. Considering the lack of empirical research on contracts in public administration per se, the second and third sections discuss how the features of tasks, incentives and ownership that have been studied in the existing literature relate closely to the features of the 'hierarchical' traditional public administration and 'market'-oriented NPM (Weber 1922; Hood 1991). In effect, it highlights the type of contracts that would be optimal under a particular governance mode in public administration to achieve efficiency in public service delivery. After 
an examination of the seeming dissonance with the 'market' mode of NPM, the fourth section discusses the growing emphasis towards public service delivery through collaborative governance. The features characterizing collaborative governance (Emerson, Nabatchi and Balogh 2012), which widely differ from pure traditional public administration and NPM, are indicative of newer contractual relations - or rather, contracts that may exist in absence of the theoretic 'agency problems'. Considering how study of public administration has lagged its practice (Shafritz and Hyde 2012), literature in public administration is yet to recognize the changing nature of relationships in collaborative governance. The chapter therefore is aimed at extending the study of public administration to encourage research which empirically tests the nuances of provision of public goods and services under collaborative contracts. To facilitate this, the last section develops a general theory of contracts and draws out certain testable propositions.

\section{AGENCY THEORY, CONTRACTS, AND JOB-DESIGN}

Asymmetric information forms the very basis of principal-agent theory wherein it is assumed that the agents have 'private' information regarding their interests and activities leading to misalignment between the goals and objectives shared between the principal and agents (Laffont and Martimort 2009). In order to address this problem, principals tend to devise means to 'control' the agents, and overcome the asymmetry in information by either investing in monitoring mechanisms or providing incentives (when monitoring is not possible), which align their respective goals, and nudge agents to function according to the principal's requirements (Rubinfeld and Pindyck 2013). Contracts therefore have an important role to play in addressing principal-agent problems since they set out the conditions of the assignment for the agent, with the principal taking appropriate action if the conditions remain unfulfilled. The contractual relations between the principal and agent form the basis of agency theory (Jensen and Meckling 1976; Jensen 1983; Eisenhardt 1989). To a large extent, the optimal contract can be ascertained through examining different features of the 'job-design'.

It has been recognized that contracts are incomplete (Hart and Holmstrom 1987). That is, contracts can never be complete enough to take into account all contingencies - arising out of either asymmetry in information between the principal and agent, or uncertainty of future conditions. This makes deciding contract optimality rather difficult. However, previous studies on agency theory have defined two contractual alternatives - behaviour-based contracts and outcome-based contracts - while seeking to determine the optimal contract for the task at hand (Eisenhardt 1989). The basic assumptions of this model are of goal conflict ${ }^{6}$ between the principal and agent, presence of an easily 


\section{Table 14.1 Optimal contracts under different agency scenarios}

\begin{tabular}{ll}
\hline $\begin{array}{l}\text { Job-Design } \\
\text { (Explanatory Variables) }\end{array}$ & $\begin{array}{l}\text { Optimal Contract } \\
\text { (Dependent Variable) }\end{array}$ \\
\hline $\begin{array}{l}\text { Under basic model } \\
\text { Presence of information systems (budgeting, reporting, monitoring) which } \\
\text { inform the principal of the agents' actions (Eccles 1985; Eisenhardt 1985; }\end{array}$ & Behaviour-based contract \\
Conlon and Parks 1990) & Behaviour-based contract \\
$\begin{array}{l}\text { When the outcome uncertainty is high, such that the cost of shifting risk to } \\
\text { agent using outcome based contract is high (Eisenhardt 1985; Amagoh 2009) }\end{array}$ & \\
$\begin{array}{l}\text { Extension of agency model } \\
\text { High task programmability, i.e. if the behaviour and activities of the agent can } \\
\text { be defined in advance (Eccles 1985; Eisenhardt 1985; Amagoh 2009) }\end{array}$ & Behaviour-based contract \\
$\begin{array}{l}\text { Easy and ready measurement of outcomes (Anderson and Schmittlein 1984; } \\
\text { Eisenhardt 1985; Ferris 1992; Amagoh 2009) }\end{array}$ & Outcome-based contract \\
$\begin{array}{l}\text { Long-term relationship between principal and agent that can reduce } \\
\text { information asymmetry (Anderson 1985; Conlon and Parks 1990; Amagoh } \\
\text { 2009) }\end{array}$ & Behaviour-based contract \\
\hline
\end{tabular}

Source: Adapted from Anderson and Schmittlein (1984), Eisenhardt (1989), Ferris (1992) and Amagoh (2009).

measured outcome of agents' activities, and the agents being more risk averse ${ }^{7}$ than the principal. The optimality of a contract has been determined using different scenarios based on the amount of information available to the principal, certainty of outcomes, task programmability, measurability of outcomes, and length of agency relationship. The optimal contract under each of the situations is presented in Table 14.1.

As summarized in Table 14.1, optimal contracts have been determined in the empirical studies performed in the private goods sectors, such as those of retail and sales, which use different measures of outcome and behaviour as dependent variables and different constructs of scenarios as explanatory variables. Outcome-based contracts have been measured through presence of manufacturer's representative or an outside agent (Anderson 1985), compensation through commission (Eisenhardt 1985, 1988), performance contingent pay (Conlon and Parks 1990), and market-based pricing ${ }^{8}$ (Eccles 1985). Behaviour-based contracts have been measured using in-house corporate sales force (Anderson 1985), compensation through fixed salary (Eisenhardt 1985, 1988), and cost-based pricing (Eccles 1985).

It is evident from the choice of variables in these studies that outcome-based contracts would go hand-in-hand with the involvement of an outside agency, performance-based compensation or commission to agents, and pricing on market principles of demand and supply. On the other hand, behaviour-based 
contracts would be associated with involvement of in-house agents, fixed salary, and lack of competition. Even though these studies are not performed on the public sector per se, the construct of behaviour-based contracts is aligned with the relations shared between principals and agents under traditional public administration - wherein even the public administrator's 'job-design' is characterized by high task programmability due to rule-based compliance, long-term employment contracts, ${ }^{9}$ and little emphasis on performance measurement. At the same time, delivery of public services under NPM is closely aligned with the construct of outcome-based contracts, wherein contracts with outside agents - such as the private sector - are drawn for specific projects, there is emphasis on performance measurement, and prior task programmability is low considering some degree of 'ownership' ${ }^{10}$ given to the outside agent in carrying out the task.

It has also been acknowledged that 'managers' would involve an outside agent only when their performance can be measured. If performance is difficult to measure, the manager would rather rely on internal service delivery given the ease in monitoring own employees (Brown, Potoski and Van Slyke 2006: 326). While the former is aligned with NPM, the latter is aligned with traditional public administration.

From the existing empirical research on agency and contracts, it is evident how closely the findings can be related to the characteristic features of public administration as identified in the literature (Weber 1922; Hood 1991). This tends to support the hypothesis of a causal linkage between public administration mode and type of contract. However, a research gap in these aforementioned studies would be their ignorance of accounting for interactions between different 'scenarios' or 'job-designs' in determining the optimal contract. That is, the research does not inform the optimal contract when several of the specified conditions may be present at a time. This aspect becomes even more important in the case of public administration research considering the simultaneous presence of features of different public administration arrangements (Pollitt 2016), and the associated presence of different collaborative modes of governance. The ensuing theoretical propositions would therefore need to be applied to study public service delivery in different countries and sectors to tease out the nature of public goods and services and the actors involved, which would help discern the differences in contracts. Another advantage of such research would be to make the study of public administration more comparative - an aspect it has been criticized to presently lack (Dahl 1947; Welch and Wong 1998; Hou et al. 2011). 


\section{Role of Incentives and Ownership}

Compensation systems in any organization are designed not only to reward productive work, but also to allocate risks (Holmstrom and Milgrom 1991). Provision of incentive pay therefore becomes a method of transferring the 'risk' of achieving outcomes onto agents. Such a risk transfer is common in business organizations which face cut-throat competition in the market. Incentive pay in the form of bonus is presented to the employees only after having undergone appraisal or performance measurement to highlight the outcomes of their efforts. Traditionally associated with fixed salaries and graded career, such compensation systems do not form a part of traditional public agencies (Holmstrom and Milgrom 1991: 27). Lack of 'incentive-based risk transfer' onto the agent therefore is aligned with behaviour-based contracts. However, with the push towards performance measurement in public administration, and decentralization and privatization, two prime purposes of measuring performance proposed to public managers have been those of 'control' over the agents, to 'motivate' them to perform better, and performance-based budgeting, while helping improve the delivery of goods and services (Schick 1966; Behn 2003). Thus, relating the above to NPM suggests there being performance-based incentive pay with a risk transfer ${ }^{11}$ onto agents using outcome-based contracts.

However, the social desirability of incentive pays, based solely on outcomes, seems to differ between different public sectors. Studies in the education sector oppose giving incentive pay to teachers (or agents) based on student test scores (Holmstrom and Milgrom 1991: 25). Test scores are regarded as a performance measure and an 'outcome' of the teacher's activity of teaching. However, compensation based solely on test scores could compromise 'quality' of teaching by emphasizing only on inculcating basic skills (which may result in the students scoring well on standardized tests) rather than developing curiosity, creativity, and higher ordered thinking among the students. This also presents a case wherein outcome uncertainty is high, since a student's test score is dependent on various other factors - intelligence, ability, home environment and not just the teacher's activity of teaching. Therefore, even if the outcome can be easily measured, an outcome-based 'incentive pay' ${ }^{12}$ contract may not be optimal as not only is the outcome uncertain and the agents (teachers) risk averse, but trading off quality (knowledge) for the sake of high outcome (high scores) may not be socially desirable either. The education sector is representative of a case where there is low certainty of a 'relationship between behaviour and outcome', that is, the activity of the agent and its outcome. In such a case, behaviour-based contracts are likely to be preferred. Put another way, if there is high certainty of a relationship between behaviour and outcome, and the 
outcomes can be measured, then an outcome-based contract would be optimal (Ferris 1992).

The above instance clearly sets out the dilemma of choosing the most optimal contract given that there are multiple tasks ${ }^{13}$ present for the agent to carry out, or the single task has several dimensions to it - leading towards the multi-dimensional ${ }^{14}$ theory of principal-agent models (Holmstrom and Milgrom 1991). Though education presents a sectoral case of public goods provision, such dilemmas are present even in the world of business wherein workers involved in production of goods not only have to increase output (outcome), but also take care of the quality of products and production equipment (behaviour). Thus, incentive pays that promote outcome-based contracts may lead to reallocation of attention towards activities that a contract explicitly promotes - increasing output at cost of quality - thereby making 'job design an important instrument for the control of incentives' (Holmstrom and Milgrom 1991: 25-26). Therefore, in the presence of multiple tasks, an understanding of the 'ownership' of assets being produced by the agent can help solve the dilemma of determining the optimal contract.

Ownership of assets produced by the agent has an important implication on incentives and contracts (Holmstrom and Milgrom 1991; Hart 2003). In case the asset returns are owned by the principal, it would not be in the interest of the agent to pursue activities geared towards asset maintenance. The interest would rather be in providing the output with negligible attention to 'quality'. It would thus be in the principal's interest to draw out a contract that is less ${ }^{15}$ reliant on incentive pay or outcomes and rather controls the agents' behaviour. The opposite would hold true if the asset returns belonged to the agent since an outcome-based contract would ensure better performance and output while there being an inherent tendency for the agent to maintain the asset as well. This can explain why franchisees of private companies, as in the case of the fast food sector, need to comply with performance-based incentives; while the company-owned stores do not receive any such incentive pay (Krueger 1991). Similarly, the incentives provided to independent contractors who own the asset are far greater than the incentives given to own employees who develop assets that are owned by the principals (Williamson 1985).

NPM has been built upon the principle of competition through the involvement of outside agents in delivery of public goods and services - be it through decentralization or privatization (Tiebout 1956; Oates 1972; Aoki 2015). Decentralization leads to delegation of decision-making power to lower levels of the government (Tiebout 1956; Lipsky 1980). It gives them ownership of the public goods and services under their jurisdiction through the funds raised locally or through performance-based budgeting, while incentivizing them to provide more public goods of a good quality (Ménard and Shirley 2005: 7). Privatization too allows private companies to earn profits on their activities of 
building and operating public goods and services (Hart 2003). Such ownership of assets by the agents under NPM supports our hypothesis of optimality of an outcome-based contract. In such a case, performance measurement and focus on outcomes itself becomes an incentive to look after the quality of public goods and services. This supports incentive payments in the contract, in the form of 'commission' to the private agents and 'additional funds' to government agencies.

\section{IMPLICATIONS FOR CONTRACTS IN PUBLIC ADMINISTRATION}

As the previous section explicates, job-design is an important instrument determining if the contracts drawn between the principal and agent are behaviour- or outcome-based. Bureaucratic employees are the agents of public service delivery in traditional public administration, functioning under fixed compensation with no incentives, nor any asset ownership. The job design therefore is aligned with the contracts being behaviour-based.

The job design under NPM is more complex, especially with the involvement of multiple external agents. The NPM principles are reminiscent of the collaborative arrangements of 'contracting-out' and 'commissioning', as discussed by Kekez, Howlett and Ramesh in the introductory chapter to the volume. They involve the private sector or other public actors as agents of the public sector (or the state) in the delivery of public goods and services.

Research on decentralization, however, has only theoretically eulogized its benefits at achieving allocative efficiency in the delivery of public goods and services (Tiebout 1956; Oates 1972). The empirical research, however sparse, has on the contrary questioned the extent of decentralization occurred in practice (Bossert 1998; Ebel and Yilmaz 2003), as well as its on the ground effectiveness in meeting public service goals - through limited competency of the agents (Lipsky 1980; Kane and Patapan 2006) or accountability dilemmas $^{16}$ (Romzek and Dubnick 1998). Unfortunately, solutions to such issues may not necessarily lie in contract optimality - considering that the process of 'delegating power' to the lower levels of government is largely political, in democracies the local governments may even be independently elected, and the aspect of genuine belief and effectiveness in 'public service' is established to be dependent on the motivations and will of the government officials than on contracts per se (Perry and Wise 1990; Ritz 2011).

The success and efficiency of public service delivery under privatization, on the other hand, is heavily dependent on contract design. Privatization of public sector activities may take several forms: transfer of ownership, disinvestment, contracting or outsourcing, competitive sourcing, ${ }^{17}$ converting from public limited ${ }^{18}$ to private company, marketization, ${ }^{19}$ commercialization, ${ }^{20}$ and 
public-private partnerships (PPP). Under the study of public administration and organization of government in the provision of public services through contracting-out or commissioning, the pertinent form of privatization to examine is PPP. ${ }^{21}$

Under PPP, a government entity contracts or commissions activities, such as that of building public infrastructure and providing public services, to a private entity in various social and economic sectors of education, health, tourism, immigration, transport, waste management, water and sanitation, security, and so on. ${ }^{22}$ PPPs have become the norm for public provision around the globe (Grimsey and Lewis 2007; OECD 2008). The public entity or government ministry therefore takes the role of principal, and the private firm that of an agent in their contractual partnership. The multi-dimensional theory of the principal-agent model and the notion of ownership have an implication on the determination of optimal contracts between the public and private actors in the PPP.

Ownership is an important consideration under 'incomplete' contracts considering that decision-making under exigencies lies with the owner of the asset (Hart 2003). At the same time, ownership also determines who benefits from the returns on investment. Therefore, in the context of provision of public services, the government or public entity would like to retain some degree of ownership. However, since the project investment is shared with the private sector, they too would like a certain degree of ownership to reap the return on their investments. As noted in the previous section, ownership has an implication on the amount of effort put into the activity of producing an outcome or asset of a good quality. This would lead us to conclude that under PPP, the private entity (agent) must have a strong sense of ownership of the asset being produced so as to not only invest in its production and delivery, but also give due consideration to the quality of asset and its maintenance. Ownership, as explicated below, raises the certainty of relationship between behaviour and outcome, making outcome-based contracts optimal under PPP.

PPP contracts ${ }^{23}$ are usually bundled - the private party not only 'builds' but also 'operates' or delivers the asset thereby giving them the incentive to build economically while taking care of the quality. ${ }^{24}$ In practice, the public agency specifies the deliverables or outcomes of the building and operation stages, while avoiding the specification of the 'means' to deliver the services that meet the objectives of the government (PPP Handbook 2012). The incompleteness ${ }^{25}$ of the contract lies in the fact that the private party can choose the process of reaching the deliverables (Hart 2003). Theory and practice confirm contracts under the PPP mode of NPM being outcome-based. However, does this imply that private entities are less risk averse or that the outcome uncertainty is low? According to research, one of the biggest advantages of PPP has been in allowing optimal allocation of risks through 'risk-sharing' (Andersen 2000). 
It allocates risk to parties who are best able to control their occurrence and economically manage them. ${ }^{26}$ This is unlike the theoretical notion of complete transfer of risk onto the agent in outcome-based contracts. Large infrastructure projects which have a long time duration ${ }^{27}$ and high stakes involved in terms of investments make all private parties risk averse..$^{28}$

However, recent years have seen a backlash against PPPs in light of their failures in delivering services economically and efficiently (Grimshaw, Vincent and Willmott 2002; Vining and Boardman 2008; Hodge and Greve 2009). In opposition to theory, ownership tends to lie with just the government, there is no risk transfer onto private agents, the contract is rigid rather than being adaptable and flexible to long-term contingencies, ${ }^{29}$ there is direct replication of the PPP toolkit instead of contextualization, high user fees ${ }^{30}$ during the commission period, and neither any learning nor skill transfer back to government (or a disregard for improving administrative supervision) - which have all made PPPs rather ineffective in achieving the outcomes which were promoted under NPM. As such, failure of NPM is reminiscent of the government failure as prophesized under the public choice theory (Tullock, Brady and Seldon 2002). There is a need of more empirical research which can set out the conditions of effective contracting, to make such public-private collaborative arrangements in public service delivery more efficient (Dayashankar and Ramesh, Chapter 4 in this volume; Migone, Chapter 5 in this volume).

\section{BEYOND PRINCIPAL-AGENT: TOWARDS COLLABORATIVE CONTRACTING}

The agency and political accountability problems that have been present and rather heightened under NPM have affected the very 'performance' of public administration by complicating the political and internal 'organizational context' (O'Toole and Meyer 2014). A system of governance that can overcome principal-agent problems while maintaining political accountability and representativeness should therefore be preferred, to not only achieve higher performance levels in public administration and raise managerial capacities, but also maintain accountability to the citizens - who embody the ultimate principals in public service.

NPM has been criticized as having led to the dysfunction of the state due to ineffective incentive and evaluation structures, dehumanizing work culture, and de-professionalizing occupations especially in the education, health, and administration sectors. This has led researchers to question as to which theoretical components of NPM must be retained and which abandoned (Widmalm 2016). Principal-agent issues in public administration seem to be rather problematic ${ }^{31}$ (O'Toole and Meyer 2014; Widmalm 2016: 127). It is interesting to find that the measures which seemingly improve public administration overlap 
with the features of collaborative governance (Emerson, Nabatchi and Balogh 2012). These include aspects of leadership, improved effectiveness through citizen- and nation-centric outcomes, knowledge building and adaptive learning, as well as reduced reliance on principal-agent theory.

The emphasis on public administration reform in favour of collaborative governance comes at a time of its immense practical and political necessity. This necessity ensues from the growing difficulty in the nature of public problems - termed as 'wicked' problems - which need to be dealt with in their entirety, than piecemeal (O'Toole 1997). At the same time, the move towards overcoming the long-held 'separation of powers' between administration and politics, while balancing the bureaucratic values of political neutrality and representativeness, mean that the principles of public administration have to go beyond their sole emphasis on efficiency towards more participatory and representative modes of public service delivery (Kaufman 1956; Vigoda 2002; Mengistu and Vogel 2006). Of course, there has always been a tension between the bureaucratic values, since a representative and participatory public administrative structure is not the most efficient (Fung 2006; Provan and Kenis 2008). Yet still, in theory, collaborative governance has features which can improve the public sector's performance by keeping political accountability, instead of hierarchical accountability or principal-agent issues, at its highest echelon (O'Toole and Meyer 2014).

Collaborative governance or 'New Public Governance', similar in its features to a network, ${ }^{32}$ takes on a more formal nature with collaborative or relational contracts between the parties involved in delivery of a public good or service (Eisenhardt 1989; Osborne 2006). This governance mode is considered to have been borne out of the failures of managerialism (as practiced under the previous regimes of traditional public administration and NPM), increasing capacity to organize a large number of actors, as well as the growing difficulties in the nature of public problems that require greater knowledge and collective efforts to solve them (Ansell and Gash 2008). Collaborative governance may be defined as a mode of governance involving individuals and organizations from the public, private and civic sphere to provide public goods and services, with the collaborations taking the form of public-private ${ }^{33}$ or other such inter-organizational arrangements (Emerson, Nabatchi and Balogh 2012). The public-private collaboration arrangements, through contracting or commissioning, have been explored under Section 3 as a component of NPM. However, in this chapter, the definition of collaborative governance is narrowed down to the governance modes wherein there is trust, reciprocity, and non-conflicting goals of the agents in public service delivery - that is, governance sans principal-agent problems.

Unlike traditional public administration and NPM, the distinction between principal and agent under the present framework of collaborative governance 
blurs, considering that the actors involved in public service provision 'engage in consensus oriented decision-making', share ownership, and work together as a team towards a common goal through shared beliefs and norms (Milward and Provan 2003: 6-8). This goes against the assumptions of the principalagent theory, along with there being little differentiation between the roles of different actors, as principal or agent, in the 'collaboration'. Therefore, the need of a contract that dictates agents' actions - in terms of behaviour or outcome - must theoretically no longer be required. However, scholarly work on collaborative and network governance does suggest persistence of a contract between the agencies involved in public provision of goods and services (Milward and Provan 2003; Bae 2009). This indicates a growing separation between the principal-agent theory and contract theory and a demise of agency theory that links the two together. Even though presence of contracts is acknowledged under collaborative governance, understanding the specific features of such 'collaborative contracts' ${ }^{34}$ must be the agenda for future studies.

Contracts that support features of collaborative governance - by involving dedicated actors or agents, clearly delegating tasks and defining deliverables under each, providing ownership of their respective functions and public assets, and maintaining contract flexibility from concerted monitoring and adaptation - can therefore increase the capacity to manage effective delivery of public services. Given that the aspects of 'trust' and 'relations' between the actors is considered prime in such collaborative arrangements, the pertinent modes of governance to study therefore become those of co-management, co-production and certification (Kekez, Howlett and Ramesh, Chapter 1 in this volume).

Contracts under co-management, co-production and certification could therefore be regarded as a 'hybrid' of the pure behaviour and outcome-based contracts that have long dominated the literature in agency theory. Under such modern collaborative governance frameworks, the principal-agent theory in public administration itself becomes passé.

\section{CONTRACT MANAGEMENT IN PUBLIC SERVICE DELIVERY: CONCLUDING REMARKS}

The synthesis of theories of principal-agent, contracts, and agency in public administration indicates that the choice between a behaviour-based, outcome-based, or collaborative contract is a function of the stage of public administration itself. From the lens of governance modes, the optimal contract between the 'actors' involved becomes a function of the specific mode of public administration, in order to achieve efficiency in public service delivery. Another theoretical contribution of the chapter lies in highlighting the blurring of the roles of principal and agent with newer collaborative governance modes. 
This suggests the necessity to shift the research agenda in public administration towards studying contractual arrangements which exist in the absence of the principal-agent problems. The implication is that in addition to the choice of contract, the very existence of principal-agent problem becomes a function of the stage, or the mode, of public administration. This can be represented as a general proposition, as explicated in Figure 14.1.

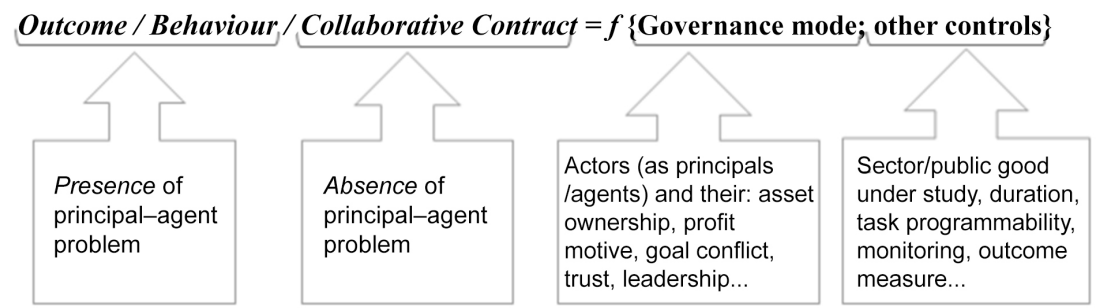

Source: Author's conceptualization.

Figure 14.1 General theory of contract management

The type of contract (outcome-based/behaviour-based/collaborative) is the dependent variable, with the governance mode ${ }^{35}$ being the primary explanatory variable. The type of contract will have a direct bearing on the efficiency in public service delivery by overcoming 'uncertainty' between the actors (principals and/or agents) involved (Williamson 1985), leading towards a general theory of contracts in public administration. As has been noted in the introductory section of this chapter, it is relevant to continue to study and acknowledge the presence of different forms of contracts, considering the argument by some scholars that traditional public administration and NPM are not completely replaced, with there being a mix of different modes of governance in the 'post-NPM' or contemporary era (Pollitt 2016; Kekez, Howlett and Ramesh, Chapter 1 in this volume).

The actors involved in public service delivery, and their notions of asset ownership, public service goals, and leadership will have a direct bearing on the governance mode in the particular sector or public good in question. The actors refer to the public sector, private sector and/or the civil society, with the transactional arrangements between them being institutionalized through the means of a contract. The optimality of the contract is necessary - to determine if efficiency in public service delivery, through the particular governance mode, will be achieved. The need for including other explanatory variables in the proposition (Figure 14.1) emerges from the literature reviewed in the previous sections of this chapter (Table 14.1), and the lack of empirical evidence on the optimal contract when several of the job-design features may be present at 
a time. This again is relevant under the present notion of governance in public administration when there may be a mix of hierarchy, market and network in a specific instance of public service delivery. Of course, specific public goods may be provided by specific governance modes; however, in addition to placing the above proposition in the case of a particular sector, ${ }^{36}$ other factors that may have a determining role on the optimal contract include the duration of contract period, measurability of outcomes, prior programmability of the task, and the presence of information mechanisms.

Of the six modes of collaborative governance identified and studied in this edited volume, the features of NPM align with the modes of contracting-out and commissioning (Dayashankar and Ramesh, Chapter 4; Migone, Chapter 5 in this volume). Under these arrangements, there is a reduction in the involvement of the public sector in direct public service delivery, along with an open market competition and provision of services through outside agents - primarily the private sector. Efficiency under such modes of governance therefore can be achieved using outcome-based contracts. However, to improve efficiency in public service delivery and raising managerial capacity by overcoming any principal-agent problem, the gap remains in understanding the nature of contracts under collaborative governance arrangements - of co-management, co-production and certification - where there may be a genuine will and trust among the agents in public service delivery (see Chindarkar, Chen and Wichelns, Chapter 6; Voorberg and van Meerkerk, Chapter 7; Vince, Chapter 8 in this volume).

Several hypotheses may be drawn out from the general proposition. A relevant one, in tone with the theme of this chapter and the volume may be that involvement of local government, citizens, and NGOs in provision of a public good, such as clean water, could indicate a governance mode of a collaborative nature - wherein all the 'actors' or agents take ownership of the asset and its quality, to provide equitable and clean water. The efficient collaborative contract can therefore be of co-management (Chindarkar, Chen and Wichelns, Chapter 6 in this volume). The hypothesis can be validated through the method of disconfirming evidence, according to which involvement of the private sector as agents in a co-management contract would prove to be inefficient (Chindarkar, Chen and Wichelns, Chapter 6 in this volume).

A corollary from the above may be that the 'profit motive' of actors involved may itself dictate the type of contract which may be drawn out in a particular context or sector. If the goal of the outside agent is to earn a profit (as is likely when the agent is the private sector), than associate itself with the goal of public service, collaborative contracts must be avoided. The optimal contract must therefore be outcome-based, using the effective contracting methods as under contracting-out or commissioning. Future research could make use of the above proposition to empirically test such hypotheses and advance the 
proposed general theory of contracts in public administration, with a specific focus on understanding collaborative contractual frameworks.

\section{NOTES}

1. The author is grateful to the editors of this volume as well as to Professor Naomi Aoki, Dr Mehmet Kerem Coban, and Kidjie Saguin for their comments and support. Previous versions of this chapter have been presented at the European Group for Public Administration Conference (EGPA 2017) in Milan, and Public Management Research Conference (PMRC 2018) in Singapore.

2. Stronghold of principal in public administration.

3. Decisions made 'adversarially' due to conflict between principal and agent.

4. From traditional public administration, to NPM, to collaborative governance.

5. Institutions here refer to the formal rules, codified in contracts, to overcome principal-agent problems and achieve efficiency in public service delivery (Acemoglu and Johnson 2005; Hodgson 2006).

6. The prime reason why the principal-agent problem exists and a contract is needed to maintain goal alignment.

7. Agents are assumed to be unable to choose between different employments/ assignments, while principals are in a better position to choose other agents for an assignment, thereby making agents more risk averse.

8. Used by companies that face high levels of competition.

9. Long-term relations are also found to be associated with a preference of the principal to use in-house agents (Anderson 1985).

10. More on 'ownership' will be discussed in the next section.

11. Risk transfer, or more specifically risk sharing, will be discussed in the next section.

12. A fixed salary with a behaviour-based contract may rather be preferred in this case.

13. Separating tasks between different agents - such that any single agent has only one task or dimension to look after - could help solve the dilemma. In the case of education, the task of teaching basic skills could be taken up by one set of teachers and that of 'higher order critical thinking' by another set of teachers.

14. As against a commonly assumed one dimensional theory wherein there is only one task required of the agent.

15. Giving incentive payments would lead to reallocation of attention or substitution of effort solely towards achieving the outcome.

16. Problems relating to hierarchical accountability emerge due to the presence of multiple agents (Ferris 1992), and those of political accountability, necessary to maintain representativeness and transparency to citizens, due to lack of relevant and credible performance measures (Kelly 2005; Kane and Patapan 2006).

17. Competition between private and public enterprises for a contract; referred to as contracting-out if private enterprise wins and contracting-in if government enterprise wins.

18. Trade on stock market.

19. Government agency operating in a market environment.

20. Transformation of a public company to an independent authority.

21. PPPs are regarded as the most economical methods of public service provision for the government (competitive bidding process, selection of the most cost-effective 
bid to carry out the project, investment by the private player), with efficiency brought in through privatization. Altogether this constitutes PPPs being regarded to deliver greater 'value for money' or VFM (Hovy 2015).

22. https://ppp.worldbank.org/public-private-partnership/agreements; accessed on 13 March 2017.

23. PPP contracts can take the form of simple contracting to more complex BOT (build, operate, and transfer), BOOT (build, operate, own, transfer), BOMT (build, operate, maintain, transfer), or BOO (build, operate, own), with the highest level of privatization under PFI (private finance initiative - design, build, finance, operate).

24. Maintenance costs are a function of quality. To bear lower costs in subsequent stages, a better quality asset would be produced in the first stage itself. Under unbundled contracts wherein the 'build', 'operate' and other stages are run by different entities, each would wish to perform their activities only as cheaply as possible, thereby trading-off quality.

25. In theory, the presence of good performance measures that specify the quality of 'building' and 'operation' in the contract can help overcome this uncertainty.

26. Risks of changes in law are allocated to the public sector, while risks of cost overruns, delays and maintenance are allocated to the private sector.

27. Although PPP contracts are long term, contrary to theory (Table 14.1), they would not translate into a preference for behaviour-based contracts since (i) all contracts are incomplete, (ii) the agent is an 'outsider', and (iii) outcomes are measurable. This indicates the importance of determining contract optimality when faced with several job-design conditions.

28. Who would participate if only the project is financeable and offers an attractive risk-return ratio.

29. Contract incompleteness provides 'escape routes' to the agent in case deliverables are not met.

30. Making the project overall uneconomical by increasing the 'cost of public good' borne by citizens.

31. Does not look into situations where there can be trust and cooperation, naturally assumes conflict.

32. Under public administration theories, a network involves multiple organizations to solve a public problem which could not have been achieved by a single organization (Agranoff and McGuire 2001). Given the fragmented nature of these networks which may be relevant to deliver a public good, aspects of leadership are important to bring the network together. This leadership may be present within the network itself, or the network may be brought together by external organization (Provan and Kenis 2008).

33. Although PPP too is a 'collaboration' between the public and private parties, its goal is to achieve coordination, rather than an institutionalized consensual and collective decision making which is central to collaborative governance (Ansell and Gash 2008: 548).

34. Also referred to as 'relational contracts' (Milward and Provan 2003: 10).

35. Representative of the 'stage' in public administration reforms.

36. Transport, education, health, waste management, etc. 